\title{
Low-grade Fibromyxoid Sarcoma: Treatment Outcomes and Efficacy of Chemotherapy
}

\author{
FLORENCE CHAMBERLAIN $^{1}$, BODIL ENGELMANN ${ }^{1}$, OMAR AL-MUDERIS ${ }^{1}$, \\ CHRISTINA MESSIOU ${ }^{1,2}$, KHIN THWAY $^{1,2}$, AISHA MIAH ${ }^{1}$, SHANE ZAIDI ${ }^{1}$, ANASTASIA CONSTANTINIDOU ${ }^{3}$, \\ CHARLOTTE BENSON $^{1}$, SPYRIDON GENNATAS ${ }^{1}$ and ROBIN L. JONES ${ }^{1,2}$ \\ ${ }^{1}$ Sarcoma Unit, The Royal Marsden NHS Foundation Trust, London, U.K.; \\ ${ }^{2}$ Institute of Cancer Research, London, U.K.; \\ ${ }^{3}$ Bank of Cyprus Oncology Center, Strovolos, Cyprus
}

\begin{abstract}
Background: Low-grade fibromyxoid sarcoma (LGFMS) is a rare sarcoma subtype with a generally indolent pattern of clinical behaviour, but treatments for advanced disease are limited. Patients and Methods: A retrospective search of a prospectively maintained institutional database identified 102 patients treated from December 1994 to August 2018. We evaluated the outcome of patients and the efficacy and safety of non-surgical therapies in LGFMS. Results: Ninety-four out of 102 (92.2\%) underwent primary resection, seven (6.9\%) were treated with systemic therapy and one (1.0\%) is currently being treated with pre-operative radiotherapy. The RECIST 1.1 response rate to first-line chemotherapy was $0 \%$, and median progression-free survival was 1.84 months (95\% confidence intervaI=0.10-3.6 months). Conclusion: Conventional systemic therapy has limited efficacy in advanced LGFMS.
\end{abstract}

Low-grade fibromyxoid sarcoma (LGFMS) is a rare sarcoma subtype predominantly affecting younger adults, with equal predilection for males and females. Sarcomas account for $1 \%$ of adult cancer and LGFMS are estimated to represent fewer than $5 \%$ of soft-tissue sarcomas $(1,2)$. LGFMS typically present in the extremities and trunk. Histologically they are described as bland spindle cell tumours with angulated nuclei, scant cytoplasm arranged in a whorled pattern with cells that are frequently immunoreactive for mucin 4 (1). Despite their relatively low-grade histology, patients with

This article is freely accessible online.

Correspondence to: Robin L. Jones, The Royal Marsden Hospital, Fulham Road, London, SW3 6JJ, U.K. Tel: +44 2078082590, Fax: +44 2078082113, e-mail: robin.jones4@ nhs.net

Key Words: Low-grade fibromyxoid sarcoma, LGFMS, chemotherapy, radiotherapy, chromosomal translocation.
LGFMS may present with an unusual distribution of metastatic disease, which can be several years after primary surgery. Therefore, it is essential that the diagnosis is confirmed by an expert soft-tissue pathologist and these patients are managed at specialist centres with experience in treating this rare tumour (1-3).

Whilst chromosomal translocations are found in approximately $20-25 \%$ of all sarcomas (4), they are found in nearly all patients with LGFMS. The $t(7 ; 16)(\mathrm{q} 32-34 ; \mathrm{p} 11)$ chromosomal translocation and the resulting fusion of FUS RNA binding protein (FUS)-cAMP responsive element binding protein 3-like 2 (CREB3L2) is the most frequently seen $(75-95 \%$ of patients with LGFMS), whilst the FUS$C R E B 3 L 1$ fusion gene is present in approximately $5 \%$ of cases of LGFMS $(2,3)$. Both the CREB3L2 and CREB3L1 genes encode transcription factors (5). A single-centre retrospective review of 14 patients with LGFMS found no association between the presence of the FUS-CREB3L2 fusion gene and local recurrence or metastatic disease (2).

Complete cytoreductive surgery with clear margins is the standard of care for localised disease with or without radiotherapy. In advanced, recurrent or metastatic disease there are currently no data to support the use of any systemic or locoregional treatments. However, re-excision of local recurrence or excision of oligo-metastatic disease may be considered in selected cases (2). In a case series of 36 patients with LGFMS treated with surgical resection with curative intent, 5- and 15-year local control rates were $83 \%$ and $79 \%$, respectively (3).

Due to its indolent clinical behaviour, LGFMS it is not considered to be particularly radiosensitive (2). Radiotherapy with concomitant chemotherapy can be used as treatment for locally advanced inoperable tumours. With often infiltrative growth pattern, pre- or post-operative radiotherapy can, as in other soft-tissue sarcomas, be considered in order to improve local control, especially for tumours of the extremities. Isolated limb perfusion (ILP) is used by some centres in 
order to enable limb-conserving surgery or avoid radiotherapy in selected patients $(6,7)$. Other localised treatments such as radiofrequency ablation (RFA) and cryoablation have been attempted to treat oligo-metastatic sarcomas $(8,9)$. However, as far as we are aware, there are no published data reporting the use of these locoregional treatments in LGFMS.

Due to its indolent behaviour and anecdotal experience, the current consensus is that systemic therapy is inactive in LGFMS (2). The best response seen in one study was stabilisation of previously progressive disease (PD) in one patient treated with trabectedin (2). There are published reports of patients being treated with anti-oestrogenic treatment, but there are no published pre-clinical or clinical evidence to support their use (2). There are currently very few published data on outcomes of patients with LGFMS, as well as the efficacy and safety of systemic or locoregional therapies. The aim of this study was to evaluate the outcome of all patients with LGFMS treated at a single specialist centre, as well as the efficacy and safety of systemic and locoregional therapies for advanced/metastatic disease.

\section{Patients and Methods}

A retrospective review of the prospectively maintained Royal Marsden Sarcoma Unit database was performed to identify patients with LGFMS treated from December 1994 to September 2018. Institutional approval was obtained prior to commencing the study (approval number: SE885) and data collection cut-off was April 2019. Patient baseline characteristics and treatment history were recorded. Since the Royal Marsden Hospital is a tertiary referral centre for sarcoma, some patients had received part of their treatment for LGFMS at other institutions. These patients were not excluded from this study unless records of their treatment history were unavailable. The diagnosis was confirmed in all cases by an expert soft-tissue pathologist. Response Evaluation Criteria in Solid Tumours (RECIST) 1.1 (10) was used to assess response to systemic therapy and Common Terminology Criteria for Adverse Events version 4.0 (11) was used to describe the severity of adverse events. Re-staging was performed after every 2-3 cycles of systemic therapy.

All patients were staged pre-operatively using either a computed tomography $(\mathrm{CT})$ or magnetic resonance imaging of the primary site and either a CT or plain radiograph of the chest. Patients with disease that was considered operable were considered for either preor post-operative radiotherapy. Re-staging was performed approximately 6-8 weeks following surgery with restaging every 36 months initially. Patients were considered for palliative radiotherapy with or without systemic chemotherapy in cases of inoperable or metastatic disease.

Pre-operative radiotherapy was given to a total dose of 50-50.4 Gy delivered in 2 Gy fractions. Post-operative radiotherapy was given to a total dose of 50.4-66 Gy delivered in 2 Gy fractions, whereas palliative radiotherapy was given to a total dose of 30-45 Gy in 2-3 Gy fractions. One patient received chemoradiotherapy to a total dose of $54 \mathrm{~Gy}$ in $1.8 \mathrm{~Gy}$ fractions with four cycles of concomitant cisplatin. Standard doses of systemic therapy were used in all patients and local guidelines were followed with regard to
Table I. Clinical characteristics of the 102 patients with low-grade fibromyxoid sarcoma.

\begin{tabular}{lc}
\hline Characteristic & Value \\
\hline Age at presentation, years & \\
Median (IQR) & $41.1(30.5-55.3)$ \\
Gender, $\mathrm{n}(\%)$ & $50(49.0)$ \\
Female & $52(51.0)$ \\
Male & $46(45.1)$ \\
Primary site, $\mathrm{n}(\%)$ & $19(18.6)$ \\
Extremity & $14(13.7)$ \\
Pelvis & $9(8.8)$ \\
Thorax & $8(7.8)$ \\
Retroperitoneum & $6(5.9)$ \\
Abdomen & \\
Head/neck & $6.5(4.0-11.0)$ \\
Tumour size, cm & \\
Median (IQR) & 86 \\
Status, $\mathrm{n}(\%)$ & 4 \\
Localised & 12 \\
Locally advanced & \\
Metastatic & $6(5.9)$ \\
Radiation, $\mathrm{n}(\%)$ & $13(12.7)$ \\
Pre-operative & $4(3.9)$ \\
Post-operative & \\
Palliative & \\
\hline
\end{tabular}

dose interruption and reduction. Patients discontinued systemic therapy on disease progression or intolerable toxicity (10). Descriptive statistics were employed as well Mann-Whitney $U$-test and the Kaplan-Meier method.

\section{Results}

Patient demographics. We identified 102 patients with LGFMS treated at the Royal Marsden Hospital between 1994 and 2018. Patient characteristics are shown in Table I. The median age at presentation was 41.1 years [interquartile range $(\mathrm{IQR})=30.5-55.3$ years $]$. Fifty patients were female $(49.0 \%)$ and 52 were male $(51.0 \%)$.

Tumour characteristics. Nine patients presented with metastatic disease and the most common site of metastasis at presentation was the lung $(n=7,6.9 \%)$. Four patients developed recurrent metastatic disease, with a time from presentation to first diagnosis of metastatic disease of $6.2,33.7,46.7$ and 55.4 months, respectively. Most tumours originated in the extremities $(n=46,45.1 \%)$ or in the pelvis $(n=19,18.6 \%)$. Tumour size was known in $97.1 \%$ patients $(99 / 102)$ and median tumour size at presentation was $6.5 \mathrm{~cm}(\mathrm{IQR}=4.0-11.0 \mathrm{~cm})$.

Surgery. Ninety-four patients $(92.2 \%)$ underwent surgical resection as primary management. Re-excision was performed in $13.8 \%$ patients (13/94) after incomplete 


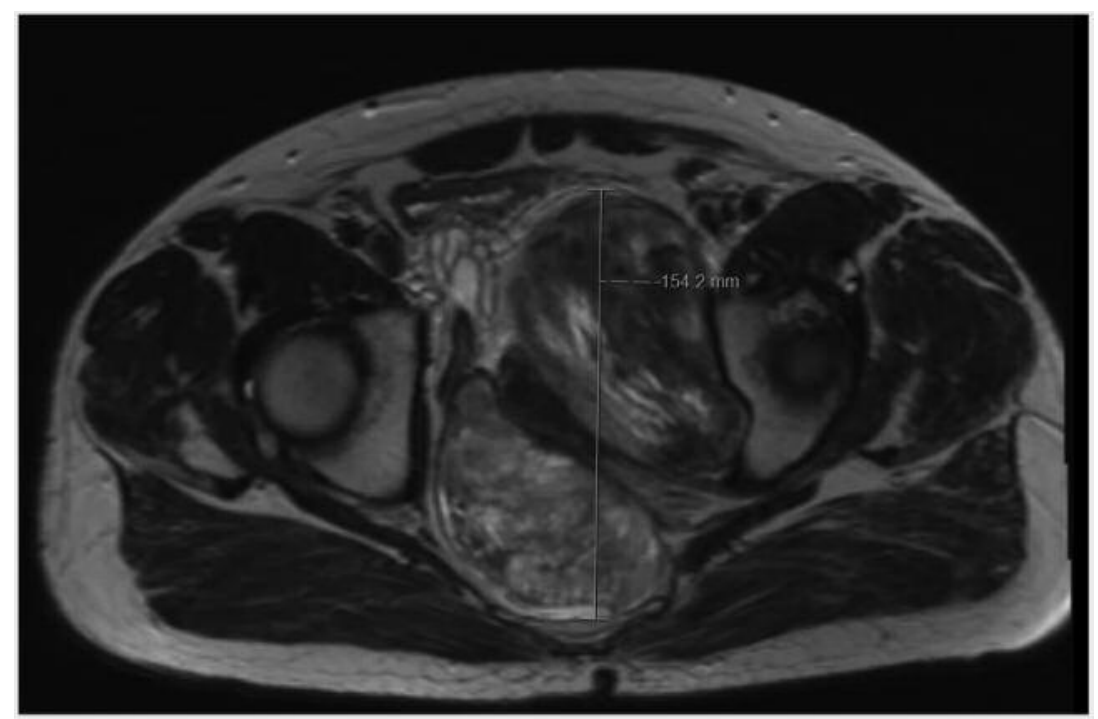

Figure 1. Magnetic resonance imaging of patient treated with concomitant chemoradiotherapy for a locally advanced inoperable pelvic low-grade fibromyxoid sarcoma.

resection of the primary tumour at first attempt. One patient $(1.0 \%)$ had a local recurrence following resection of a primary tumour resected at our Institution. This patient went on to have two further resections of the primary tumour, 6 years following the primary excision. A total of $77.7 \%$ of patients (73/94) were treated with surgery alone and the median time from presentation to death or last follow up was 59.1 months (IQR=24.9-82.4 months) for this cohort.

Of the eight patients $(7.8 \%)$ who did not undergo primary resection, one had metastatic disease at presentation, one declined surgery, one is currently being treated with preoperative radiotherapy, and five had inoperable disease. One patient with inoperable disease received definitive radiotherapy with concomitant chemotherapy as their primary treatment. For patients treated without surgery, local or systemic treatments $(\mathrm{n}=5)$, the median time from presentation to death was 37.7 months (IQR=32.7-76.6 months).

Radiotherapy. Pre- or post-operative radiotherapy was employed in 20 patients. Six patients received pre-operative radiotherapy prior to resection of their primary tumour and five out of six patients treated with pre-operative radiotherapy were alive at the time of analysis; the median time from presentation to death or last follow-up was 32.2 months (IQR=16.4-41.8 months). In 13 patients, radiotherapy was given post-operatively, for 10 of those after resection of the primary tumour, and for two after resection of local recurrence. Seven out of 13 patients were alive at the time of analysis, four had died, and the status of two patients was unknown (15.4\%). One patient had post-operative radiotherapy after resection of an isolated chest wall metastasis. In those who had post-operative radiotherapy to the primary tumour, the median time from presentation to death or last follow-up was 51.1 months (IQR=41.2-85.0 months). Of the 15 patients treated with pre- or post-operative radiotherapy, the median time from presentation to death or last follow-up was 50.8 months (IQR=30.3-57.7 months). Three patients received palliative radiotherapy: One for pelvic metastatic disease, another to a primary tumour in the mandibular area, and one to the primary tumour.

One patient was treated with concomitant chemoradiotherapy for a locally advanced inoperable primary tumour. This patient presented with pelvic pain and faecal incontinence. Imaging demonstrated a large pelvic mass (Figure 1) and biopsies confirmed LGFMS. The tumour was deemed inoperable due to the high likelihood of an R2 resection and potential surgical morbidity and mortality. The patient was therefore offered definitive radiotherapy with concomitant weekly cisplatin chemotherapy with 54 Gy in 2 Gy fractions as their primary treatment. Prior to radiotherapy, a de-functioning colostomy was offered to palliate symptoms. Pain significantly improved following treatment and the post treatment scans demonstrated stable disease (SD). However, at 56 months after initial presentation, a surveillance CT scan demonstrated a new $27 \mathrm{~mm}$ segment 6 liver lesion, whilst the pelvic lesion remained stable in size and appearance (Figure 2). A magnetic resonance imaging scan was performed to further characterise the new liver lesion which appeared to be consistent with a metastatic deposit of LGFMS. A positronemission tomography-CT confirmed further sites of metastatic 
spread in the pelvis. The patient underwent resection of the solitary deposit in the liver with a plan for further palliative radiotherapy to the bone metastasis in the near future.

Systemic therapy. In this cohort, seven patients (6.9\%) were treated with systemic therapy. The indication for systemic therapy was palliation of metastatic or recurrent disease. The overall RECIST 1.1 (10) response rate was 0\%. See Table II for treatment details. For patients treated with surgery and systemic therapy $(n=6)$, the median time from presentation to death or last follow-up was 35.0 months (IQR=40.1-150.1 months).

Endocrine therapy. Endocrine agents used included tamoxifen in a patient erroneously given the diagnosis of a desmoid tumour prior to pathology review at the Royal Marsden Hospital. Since the patient had derived clinical benefit from tamoxifen and had RECIST SD for 12 months, it was deemed that the tumour was hormone-sensitive. Following disease progression on tamoxifen, exemestane was commenced but disease progression was documented following 8 months of this treatment. The patient was then commenced on Caelyx.

Chemotherapy. Seven patients (7/102) were treated with chemotherapy. Agents used in the first-line setting were doxorubicin in four, Caelyx in one and combination ifosfamide and doxorubicin in one. Two patients received ifosfamide as a second-line treatment and Caelyx was used in the third-line for two patients. Trabectedin was used as a third-line and fourthline treatment in two patients, respectively. Median overall survival from the start of first-line chemotherapy was 120.4 months $(95 \%$ confidence interval=56.3-184.5 months). Median progression-free survival from the start of first-line chemotherapy to first progression was 1.84 months $(95 \%$ confidence intervaI $=0.10-3.6)$. One patient had maintained disease stability (as per RECIST 1.1) on trabectedin given in the third-line for 17.5 months (discontinued due to PD) and on pazopanib given in the fourth-line for 87 months at time of study. Of the seven patients treated with chemotherapy, FUSCREB3L2/FUS-CREB3L1 translocations were seen in four patients (negative in two patients and unknown in one patient).

Three patients developed complications from chemotherapy. One developed grade 3 cardiac failure and nonneutropaenic sepsis after 1 cycle of Caelyx, requiring admission to hospital and referral to a cardiology unit for the management of cardiotoxicity. The patient eventually resumed Caelyx after a 10 -week delay and at a $40 \%$ dose reduction. Despite these measures, the patient experienced grade 3 cardiac and haematological toxicities as well as PD, and the treatment was discontinued. Another patient experienced grade 4 nausea after the first cycle of doxorubicin and required a subcutaneous syringe pump with anti-emetics in subsequent cycles. The same patient developed grade 3 neutropaenic sepsis after cycle 5 of doxorubicin with cellulitis as the

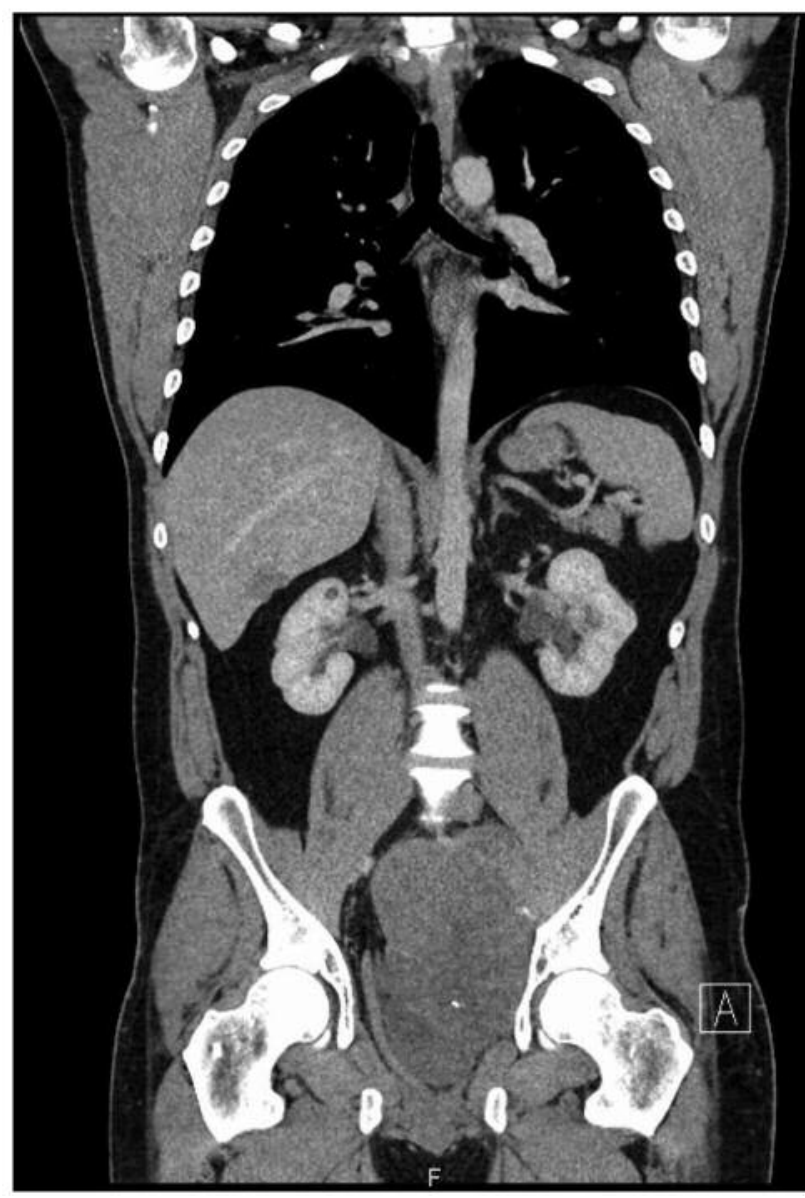

Figure 2. Computed tomographic scan of patient treated with concomitant chemoradiotherapy, demonstrating development of new liver metastasis after 56 months.

confirmed source. The third patient required a dose reduction of ifosfamide due to frank haematuria. A Kaplan-Meier curve for survival probability for patients treated with first-line systemic chemotherapy is shown in Figure 3.

Targeted systemic therapy. One patient has been treated in the fourth-line setting with pazopanib, an oral tyrosine kinase inhibitor (TKI) targeting angiogenesis and has since continued this treatment for the past 8 years with SD as best response. Two patients were treated within phase II clinical trials of the oral TKIs axitinib and brivanib.

Locoregional therapy. One patient was treated with RFA to an isolated lung metastasis at another institution; however, this was ineffective in achieving local control, with progression of the treated lung metastasis and other distant sites of disease following RFA treatment. No patients were treated with RFA or ILP for LGFMS at our Institution. 


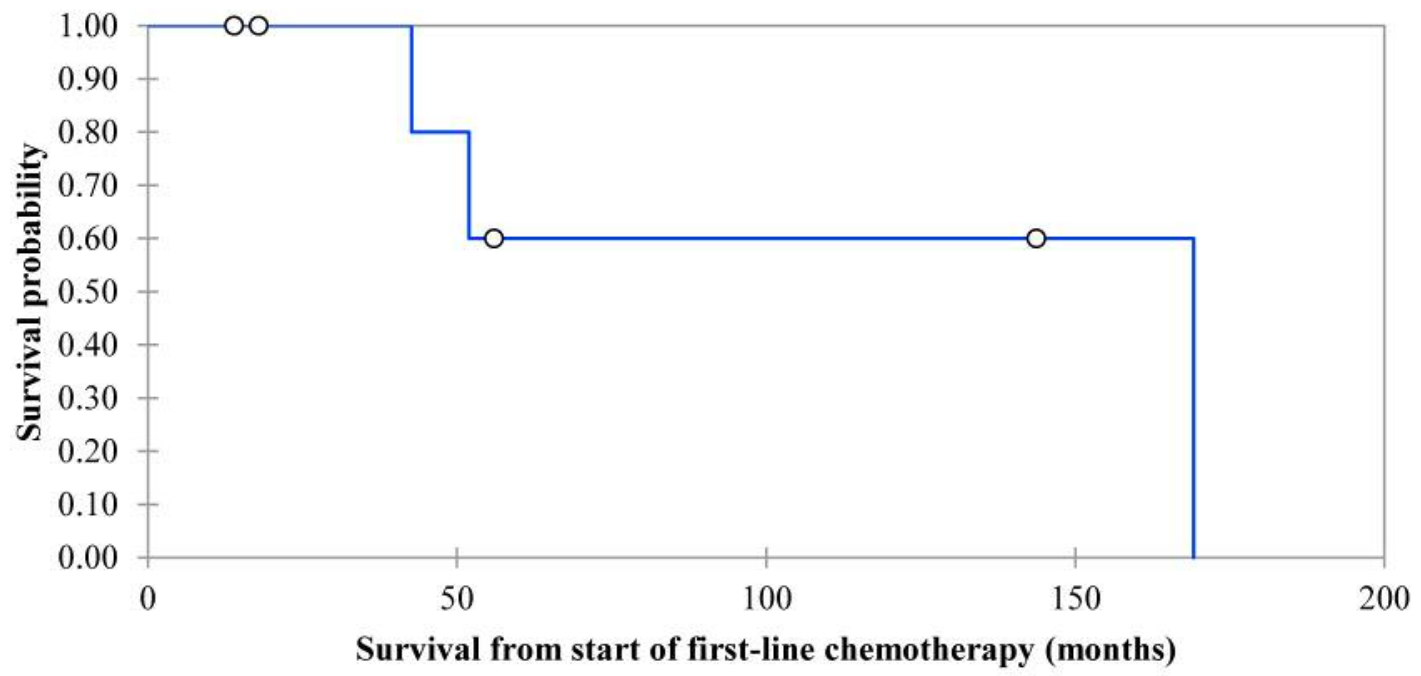

Figure 3. Kaplan-Meier curve for overall survival of patients following first-line systemic chemotherapy for low-grade fibromyxoid sarcoma.

Table II. Outcomes of patients with low-grade fibromyxoid sarcoma treated with systemic treatment for recurrent or metastatic disease.

\begin{tabular}{|c|c|c|c|c|c|c|c|c|}
\hline Patient & $\begin{array}{l}\text { FUS- } \\
\text { CREB3L2 } \\
\text { fusion }\end{array}$ & $\begin{array}{l}\text { Systemic } \\
\text { treatment }\end{array}$ & $\begin{array}{l}\text { PFS from start } \\
\text { of treatment to } \\
\text { first PD (months) }\end{array}$ & $\begin{array}{c}\text { Best } \\
\text { response* }\end{array}$ & $\begin{array}{c}\text { Reason for } \\
\text { treatment } \\
\text { discontinuation }\end{array}$ & Status & $\begin{array}{l}\text { OS from start of } \\
\text { first treatment } \\
\text { (months) }\end{array}$ & Toxicity \\
\hline 1 & Positive & Caelyx & 1.84 & PD & $\mathrm{PD}$ & $\begin{array}{l}\text { Alive with } \\
\text { disease }\end{array}$ & 16.5 & $\begin{array}{l}\text { Caelyx: Grade } \\
3 \text { heart failure }\end{array}$ \\
\hline 2 & Positive & $\begin{array}{l}\text { Doxorubicin } \\
\text { Ifosfamide }\end{array}$ & $\begin{array}{l}1.51 \\
3.72\end{array}$ & $\begin{array}{l}\mathrm{PD} \\
\mathrm{SD}\end{array}$ & $\begin{array}{c}\mathrm{PD} \\
\text { Completed } \\
\text { treatment }\end{array}$ & $\begin{array}{l}\text { Died of } \\
\text { disease }\end{array}$ & 14.0 & Nil \\
\hline 3 & Positive & $\begin{array}{c}\text { Doxorubicin } \\
\text { Phase II trial } \\
\text { Caelyx } \\
\text { Trabectedin }\end{array}$ & $\begin{array}{l}4.11 \\
9.44 \\
4.77 \\
\\
8.75\end{array}$ & $\begin{array}{l}\text { SD } \\
\text { SD } \\
\text { SD }\end{array}$ & $\begin{array}{c}\text { PD } \\
\text { PD } \\
\text { Completed } \\
\text { treatment } \\
\text { PD }\end{array}$ & $\begin{array}{l}\text { Alive with } \\
\text { disease }\end{array}$ & 106.1 & $\begin{array}{l}\text { Doxorubicin: } \\
\text { Grade } 3 \text { nausea, } \\
\text { grade } 3 \text { febrile } \\
\text { neutropoenia }\end{array}$ \\
\hline 4 & $\begin{array}{c}\text { Unknown } \\
\text { (insufficient sample } \\
\text { for testing) }\end{array}$ & $\begin{array}{c}\text { Tamoxifen } \\
\text { Exemestane } \\
\text { Caelyx }\end{array}$ & $\begin{array}{l}6.51 \\
7.79 \\
2.76\end{array}$ & $\begin{array}{l}\text { SD } \\
\text { SD } \\
\text { SD }\end{array}$ & $\begin{array}{l}\text { PD } \\
P D \\
P D\end{array}$ & $\begin{array}{l}\text { Died of } \\
\text { disease }\end{array}$ & 59.3 & Nil \\
\hline 5 & Negative & $\begin{array}{l}\text { Doxorubicin } \\
\text { Ifosfamide }\end{array}$ & $\begin{array}{l}1.32 \\
1.58\end{array}$ & $\begin{array}{l}\text { PD } \\
\text { PD }\end{array}$ & $\begin{array}{l}\text { PD } \\
\text { PD }\end{array}$ & $\begin{array}{l}\text { Died of } \\
\text { disease }\end{array}$ & 7.0 & $\begin{array}{l}\text { Ifosfamide: Grade } \\
1 \text { haematuria }\end{array}$ \\
\hline 6 & Positive & Doxorubicin & 1.18 & $\mathrm{PD}$ & $\mathrm{PD}$ & $\begin{array}{l}\text { Died of } \\
\text { disease }\end{array}$ & 22.6 & Nil \\
\hline 7 & Negative & $\begin{array}{c}\text { Ifosfamide }+ \\
\text { Doxorubicin } \\
\text { Phase II trial } \\
\text { Trabectedin } \\
\text { Pazopanib }\end{array}$ & $\begin{array}{c}3.02 \\
\\
8.29 \\
17.49 \\
87.02\end{array}$ & $\begin{array}{l}\text { SD } \\
\text { SD } \\
\text { SD } \\
\text { SD }\end{array}$ & $\begin{array}{l}\text { PD } \\
\text { PD } \\
\text { PD } \\
\text { N/A }\end{array}$ & $\begin{array}{c}\text { Alive with } \\
\text { disease }\end{array}$ & 166.1 & $\begin{array}{l}\text { Phase II trial agent: } \\
\text { Mucositis, thyroid } \\
\text { dysfunction, rash } \\
\text { and fatigue }\end{array}$ \\
\hline
\end{tabular}

PD: Progressive disease; OS: overall survival; SD: stable disease. *As per RECIST 1.1 (10).

\section{Discussion}

Due to its rarity, there are limited published data regarding the treatment and outcome of LGFMS. It can cause significant morbidity with a paucity of evidence to guide management in the advanced/metastatic setting. To our knowledge, this single-centre retrospective study of LGFMS is the largest published cohort to date $(2,12-20)$. Our data provide a benchmark for future studies of systemic therapy in advanced LGFMS. An electronic search of 
ClinicalTrials.gov on $12^{\text {th }}$ September 2019 using the term "Low Grade Fibromyxoid Sarcoma" yielded one result (21). However, other early phase clinical trials in solid tumours may also include LGFMS as part of an 'all comers' cohort.

Most patients $(92.2 \%)$ treated at our centre underwent primary surgical resection with only a few (13.8\%) requiring re-excision for locally recurrent disease.

Several phase I and II studies of targeted agents have included patients with LGFMS. In the multi-centre phase II AXI-STS trial (22) 71 patients with a range of soft-tissue sarcomas, including one patient with LGFMS, were enrolled. Preliminary data presented in 2014 demonstrated a 10\% RECIST 1.1 (10) response rate to the TKI axitinib and median progression-free survival of 4.2 months across all sarcoma subtypes, however, efficacy of axitinib in LGFMS is unknown (22). The ongoing multi-centre PAZANTIS phase II/III trial randomises patients with non-rhabdomyosarcoma soft tissue sarcomas to neoadjuvant chemoradiation or neo-adjuvant radiation with or without the oral TKI pazopanib and results are awaited (21). However, to our knowledge there are no published studies demonstrating efficacy of targeted agents in treating LGFMS.

Despite only $6.9 \%$ of patients receiving systemic treatments in this study, the RECIST 1.1 response rate to first-line chemotherapy was $0 \%$, with a median progressionfree survival of 1.84 months. These data indicate that currently available conventional systemic therapies have limited efficacy in LGFMS. In addition, there was no significant difference in median time from presentation to death compared to those treated without systemic treatments for recurrent or advanced disease (47.3 vs. 50.7 months, $p=0.837$ ), suggesting that conventional chemotherapy is inactive in this subtype. Patients should therefore be offered the option of participation in clinical trials.

In our study, 21 patients received radiotherapy with either curative or palliative intent. Our limited experience of the two patients with metastatic LGFMS treated with radiotherapy suggests limited activity in this setting. The phase I-II TRASTS study, which is now closed to recruitment, explores the use of combination trabectedin and radiotherapy to treat a variety of soft-tissue sarcomas including LGFMS and the results are awaited (23). The role of pre-/post-operative radiation in extremity/trunk soft-tissue sarcomas is well established through a number of well conducted, randomized trials (24-26). To date, we have no experience of using locoregional therapies such as RFA, cryoablation and ILP to achieve disease control but these modalities warrant further investigation.

There are currently no putative prognostic biomarkers for LGFMS; however, the FUS-CREB3L2 and FUS-CREB3L1 fusion genes, as well as the pathways influenced by the $C R E B 3 L 2$ and $C R E B 3 L 1$ wild-type genes, may be helpful in building a greater understanding of the pathogenesis of this rare tumour type and in developing effective therapeutic agents.

\section{Authors' Contributions}

FC: Designed the study, collected and analysed the data, wrote the manuscript; BE: edited the article; OA-M: collected the data; CM, KT, AM, SZ, AC, CB, SG: Edited the article; RLJ: Conceived and designed the study and edited the article.

\section{Conflicts of Interest}

FC, BE, OA-M, KT, AM, SZ, AC, CB, SG: None; CM: receipt of speaker honoraria Celgene, Janssen; RLJ: Receipt of honoraria and consultation fees (Adaptimmune; Blueprint; Clinigen; Eisai; Epizyme; Daichii; Deciphera; Immunedesign; Lilly; Merck; Pharmamar)

\section{Acknowledgements}

This research did not receive any specific grant from funding agencies in the public, commercial, or not-for-profit sectors. This work was undertaken in The Royal Marsden NHS Foundation Trust together with The Institute of Cancer Research which receives BRC funding through the National Institute for Health Research (NIHR).

\section{References}

1 Mohamed M, Fisher C and Thway K: Low-grade fibromyxoid sarcoma: Clinical, morphologic and genetic features. Ann Diagn Pathol 28: 60-67, 2017. PMID: 28648941. DOI: 10.1016/ j.anndiagpath.2017.04.001

2 Maretty-Nielsen K, Baerentzen S, Keller J, Dyrop HB and Safwat A: Low-grade fibromyxoid sarcoma: incidence, treatment strategy of metastases, and clinical significance of the FUS Gene. Sarcoma 2013: 256280, 2013. PMID: 23818812. DOI: $10.1155 / 2013 / 256280$

3 Zagars GK, Ballo MT, Pisters PWT, Pollock RE, Patel SR, Benjamin RS and Evans HL: Prognostic factors for patients with localized soft-tissue sarcoma treated with conservation surgery and radiation therapy: An analysis of 1225 patients. Cancer 10: 2530-2543, 2003. PMID: 12733153. DOI: 10.1002/cncr.11365

4 Cesne A Le, Cresta S, Maki RG, Blay JY, Verweij J, Poveda A, Casali PG, Balaña C, Schöffski P, Grosso F, Lardelli P, Nieto A, Alfaro $\mathrm{V}$ and Demetri GD: A retrospective analysis of antitumour activity with trabectedin in translocation-related sarcomas. Eur J Cancer 48(16): 3036-3044, 2012. PMID: 22749255. DOI: $10.1016 /$ j.ejca.2012.05.012

5 Mertens F, Fletcher CDM, Antonescu CR, Coindre JM, Colecchia M, Domanski HA, Downs-Kelly E, Fisher C, Goldblum JR, Guillou L, Reid R, Rosai J, Sciot R, Mandahl N and Panagopoulos I: Clinicopathologic and molecular genetic characterization of low-grade fibromyxoid sarcoma, and cloning of a novel FUS/CREB3L1 fusion gene. Lab Investig 85(3): 408415, 2005. PMID: 15640831. DOI: 10.1038/labinvest.3700230

6 Provenzano S, Raimondi A, Bertulli RM, Colia V, Renne SL, Collini P, Dagrada G, Callegaro D, Fiore M, Greco FG and Casali PG: Response to isolated limb perfusion and chemotherapy with epirubicin plus ifosfamide in a metastatic malignant ossifying fibromyxoid tumor. Clin Sarcoma Res 7: 20, 2017. PMID: 29299229. DOI: 10.1186/s13569-017-0086-2

7 Jakob J, Smith HG, Wilkinson MJ, Pencavel T, Miah AB, Thomas JM, Tunn P-U, Pilz LR, Strauss DC, Hohenberger P and 
Hayes AJ: Regional chemotherapy by isolated limb perfusion prior to surgery compared with surgery and post-operative radiotherapy for primary, locally advanced extremity sarcoma: a comparison of matched cohorts. Clin Sarcoma Res 8: 12, 2018. PMID: 29988594. DOI: 10.1186/s13569-018-0098-6

8 Susa M, Kikuta K, Nakayama R, Nishimoto K, Horiuchi K, Oguro S, Inoue $M$, Yashiro $H$, Nakatsuka S, Nakamura $M$, Matsumoto M, Chiba K and Morioka H: CT guided cryoablation for locally recurrent or metastatic bone and soft tissue tumor: Initial experience. BMC Cancer 16(1): 798, 2016. PMID: 27737652. DOI: $10.1186 / \mathrm{s} 12885-016-2852-6$

9 Gronchi A, Guadagnolo BA and Erinjeri JP: Local ablative therapies to metastatic soft tissue sarcoma. Am Soc Clin Oncol Educ Book 35: e566-575, 2016. PMID: 27249769. DOI: 10.1200/EDBK_157450

10 Eisenhauer EA, Therasse P, Bogaerts J, Schwartz LH, Sargent D, Ford R, Dancey J, Arbuck S, Gwyther S, Mooney M, Rubinstein L, Shankar L, Dodd L, Kaplan R, Lacombe D and Verweij J: New response evaluation criteria in solid tumours: Revised RECIST guideline (version 1.1). Eur J Cancer 45(2): 228-247, 2009. PMID: 19097774. DOI: 10.1016/j.ejca.2008.10.026

11 National Institute of Cancer: Common Terminology Criteria for Adverse Events (CTCAE), Version 4.0, DCTD, CTI, NIH, DHHS, 2009.

12 Mastoraki A, Strigkos T, Tatakis FP, Christophi A and Smyrniotis V: Recurrent low-grade fibromyxoid sarcoma of the neck: report of a case and review of the literature. Indian J Surg Oncol 6(3): 296299, 2015. PMID: 27217684. DOI: 10.1007/s13193-015-0429-5

13 Chatterjee J, Howden S, Saso S, Ghaem-Maghami S, McIndoe A and Dina R: Metastatic low-grade fibromyxoid sarcoma of the broad ligament: A case report and literature review. J Obstet Gynaecol 36(7): 852-854, 2016. PMID: 27185563. DOI: 10.1080/01443615.2016.1174819

14 Shibata S, Shiraishi K, Yamashita H, Kobayashi R and Nakagawa K: Radiation-induced low-grade fibromyxoid sarcoma of the chest wall nine years subsequent to radiotherapy for breast carcinoma: A case report. Oncol Lett 11(4): 25202524, 2016. PMID: 27073510. DOI: 10.3892/ol.2016.4221

15 Dobin SM, Malone VS, Lopez L and Donner LR: Unusual histologic variant of a low-grade fibromyxoid sarcoma in a 3year-old boy with complex chromosomal translocations involving 7q34, 10q11.2, and 16p11.2 and Rearrangement of the FUS Gene. Pediatr Dev Pathol 16(2): 86-90, 2012. PMID: 23075075. DOI: 10.2350/12-07-1225-CR.1

16 Menon S, Krivanek M and Cohen R: Low-grade fibromyxoid sarcoma, a deceptively benign tumor in a 5-year-old child. Pediatr Surg Int 28(2): 211-213, 2012. PMID: 22130782. DOI: 10.1007/s00383-011-3024-z

17 Shidham VB, Ayala GE, Lahaniatis JE and Garcia FU: Lowgrade fibromyxoid sarcoma: Clinicopathologic case report with review of the literature. Am J Clin Oncol 22(2): 150-155, 1999. PMID: 10199449. DOI: 10.1097/00000421-199904000-00009
18 Canpolat C, Evans HL, Corpron C, Andrassy RJ, Chan KW, Eifel P, Elidemir O and Raney B: Fibromyxoid sarcoma in a four-year-old child: Case report and review of the literature. Med Pediatr Oncol 27(6): 561-564, 1996. PMID: 8888818. DOI: $10.1002 /(\mathrm{SICI}) 1096-911 \mathrm{X}(199612) 27: 6<561:$ :AIDMPO10>3.0.CO;2-B

19 Arancio M, Ranzoni S, Delsignore A, Maffei N, Landi G, Mina A, Marcato $M$ and Martinengo C: Fibromyxoid sarcoma of the kidney. A case report. Urol J 77(4): 263-266, 2018. PMID: 21234870 .

20 Seto T, Song M-N, Trieu M, Yu J, Sidhu M, Liu C-M, Sam D and Pan M: Real-World experiences with pazopanib in patients with advanced soft tissue and bone sarcoma in Northern California. Med Sci 7(3), 2019. PMID: 30889920. DOI: 10.3390/medsci7030048

21 ClinicalTrials gov: Radiation therapy with or without combination chemotherapy or pazopanib hydrochloride before surgery in treating patients with newly diagnosed non-rhabdomyosarcoma soft tissue sarcomas that can be removed by surgery. US Natl Libr Med, 2014. Available at: https://clinicaltrials.gov/ct2/show/ NCT02180867 (last accessed September 12, 2019).

22 ClinicalTrials.gov: A study of axitinib in patients with advanced angiosarcoma and other soft tissue sarcomas (Axi-STS). US Natl Libr Med, 2010. Available at: https://clinicaltrials.gov/ ct2/show/NCT01140737 (last accessed September 12, 2019).

23 ClinicalTrials.gov: Phase I-II trial, multicenter, open, exploring trabectedin plus radiotherapy in soft tissue sarcoma patients (TRASTS). US Natl Libr Med, 2014. Available at: https:// clinicaltrials.gov/ct2/show/NCT02275286 (last accessed September 12, 2019).

24 Yang JC, Chang AE, Baker AR, Sindelar WF, Danforth DN, Topalian SL, DeLaney T, Glatstein E, Steinberg SM, Merino MJ and Rosenberg SA: Randomized prospective study of the benefit of adjuvant radiation therapy in the treatment of soft tissue sarcomas of the extremity. J Clin Oncol 16(1): 197-203, 1998. PMID: 9440743. DOI: 10.1200/JCO.1998.16.1.197

25 Pisters PW, Harrison LB, Leung DH, Woodruff JM, Casper ES and Brennan MF: Long-term results of a prospective randomized trial of adjuvant brachytherapy in soft tissue sarcoma. J Clin Oncol 14(3): 859-868, 1996. PMID: 8622034. DOI: 10.1200/JCO.1996.14.3.859

26 O’Sullivan B, Davis AM, Turcotte R, Bell R, Catton C, Chabot P, Wunder J, Kandel R, Goddard K, Sadura A, Pater J and Zee B: Preoperative versus postoperative radiotherapy in soft-tissue sarcoma of the limbs: a randomised trial. Lancet 359: 2235-2241, 2002. PMID: 12103287. DOI 10.1016/S0140-6736(02)09292-9

Received September 29, 2019 Revised November 8, 2019 Accepted November 12, 2019 